\title{
Sustained hyperferritinemia in a child with macrophage activation syndrome secondary to systemic juvenile idiopathic arthritis - perforinopathy: case based review
}

\author{
Mustafa Çakan ${ }^{1}$, Nuray Aktay-Ayaz¹, Hakan Gemici², Agageldi Annayev ${ }^{3}$, Agop Çıtak ${ }^{3}$, \\ Arzu Akçay ${ }^{4}$, Gülyüz Öztürk ${ }^{4}$ \\ Clinics of ${ }^{1}$ Pediatric Rheumatology, and ${ }^{2}$ Pediatrics, Kanuni Sultan Süleyman Research and Training Hospital, ${ }^{3}$ Department \\ of Pediatrics, and ${ }^{4}$ Department of Pediatric Hematology and Oncology, Acibadem University Atakent Hospital, Istanbul, \\ Turkey.E-mail: mustafacakan@hotmail.com \\ Received: 24th April 2017, Revised: 5th August 2017, Accepted: 23rd September 2017
}

SUMMARY: Çakan M, Aktay-Ayaz N, Gemici H, Annayev A, Çıtak A, Akçay A, Öztürk G. Sustained hyperferritinemia in a child with macrophage activation syndrome secondary to systemic juvenile idiopathic arthritis - perforinopathy: case based review. Turk J Pediatr 2018; 60: 598-603.

Systemic juvenile idiopathic arthritis is a subtype of juvenile idiopathic arthritis and characterized by arthritis and many systemic features like fever, rash, hepatosplenomegaly, lymphadenopathy and serositis. Macrophage activation syndrome is the most dreadful complication of systemic juvenile idiopathic arthritis and can cause mortality and morbidity if not recognized and treated early and aggressively.

Hemophagocytic lymphohistiocytosis (HLH) is characterized by diminished or absent activities of natural killer cells and cytotoxic $\mathrm{T}$ lymphocytes leading to cytokine storm and uncontrolled activation of $\mathrm{T}$ cells and macrophages. Primary (familial) HLH is a group of autosomal recessive disorders caused by mutations in the perforin and other related genes and distinctive for onset during early infancy and high rate of mortality. Secondary HLH may be caused by infectious, oncologic and rheumatologic disorders. The term Perforinopathy is used to describe cases with classical familial HLH and also for cases with familial HLH gene mutations but not following a classical familial HLH course.

Herein we report a case of chronic perforinopathy in which clinical symptoms started with systemic juvenile idiopathic arthritis and severe macrophage activation syndrome that needed plasma exchange and extracorporeal membrane oxygenation during acute period and ongoing interleukin-1 blockage for sustained hyperferritinemia.

Key words: hyperferritinemia, macrophage activation syndrome, perforin A91V, perforinopathy, systemic juvenile idiopathic arthritis.

Juvenile idiopathic arthritis (JIA) is the most common cause of chronic arthritis in children. ${ }^{1}$ The diagnosis of JIA is made by the presence of arthritis for more than 6 weeks in a child younger than 16 years of age and in whom there is no other identified cause for arthritis. ${ }^{2}$ JIA is not a homogenous disease and has several subtypes. Classification systems were developed for JIA and the last one, ILAR classification, divides JIA into 7 subtypes. ${ }^{1}$ Systemic JIA (sJIA) comprises $5 \%$ to $15 \%$ of children with JIA. sJIA is characterized by arthritis and systemic features such as fever, rash, serositis, lymphadenopathy and hepatosplenomegaly. ${ }^{2}$ As sJIA has many accompanying systemic features, follows a course different from other JIA subtypes and lacks association with certain HLA types and autoantibodies, debate is whether it should be included in the category of JIA, or whether it should be considered as an autoinflammatory disease. ${ }^{1}$

Hemophagocytic lymphohistiocytosis (HLH) is a term that describes a spectrum of 
disorders characterized by accumulation of well-differentiated mononuclear cells with a macrophage phenotype exhibiting hemophagocytic activity. ${ }^{3} \mathrm{HLH}$ is divided as primary (familial) HLH and secondary HLH. Secondary HLH may be caused by infectious, oncologic and rheumatologic diseases ${ }^{4,5}$. Systemic JIA, Kawasaki disease and systemic lupus erythematosus are the most common causes of rheumatologic disorders that can lead to secondary HLH also known as macrophage activation syndrome (MAS). ${ }^{6}$ Perforinopathy is the term suggested to be used by Voskoboinik et al. $^{7}$ to describe patients with complete or partial loss of perforin function that can lead to classical familial HLH or late onset MAS, and hematological malignancy.

\section{Case Report}

A 9-year-old boy was admitted to the hospital with the complaints of fever and arthralgia for three weeks. He was hospitalized in another center for a week because of the fever. As fever did not subside, and slowly progressing respiratory distress started, he was referred to our emergency room. He had jugular venous distension, mild dyspnea and cardiac sounds were deeply located. Chest X-ray revealed no pneumonic infiltration but cardiomegaly. Echocardiographic examination showed $30 \mathrm{~mm}$ pericardial effusion. The child was transferred to pediatric intensive care unit (PICU) and pericardiocentesis, that yielded serosanguineous fluid, was performed. The child was admitted to pediatric rheumatology ward. He had diurnal fever (peaking to $39.5^{\circ} \mathrm{C}$ ), accompanied by evanescent macular rash, myalgia and arthralgia. Arthritis on the left knee and left ankle and $2 \mathrm{~cm}$ splenomegaly was noticed. He was the first child of the non-consanguineous healthy parents and had a healthy younger brother. The family stated that the child did not have any known disease and was totally healthy until 3 weeks ago.

Laboratory tests showed leukocytosis, anemia, thrombocytosis, high acute phase reactants, hypoalbuminemia, and hyperferritinemia (ferritin: $13.670 \mathrm{ng} / \mathrm{ml}$ ) (Table I - $1^{\text {st }}$ day results). Bone marrow aspiration did not show any malignant cells or hemophagocytic cells. Blood, urine and pericardial fluid cultures, bacterial and viral serology studies did not yield any possible causative agent. Especially, EbsteinBarr virus and cytomegalovirus serologic and DNA studies that were twice repeated became negative. Thorax and abdominal computerized tomography (CT) examinations did not show

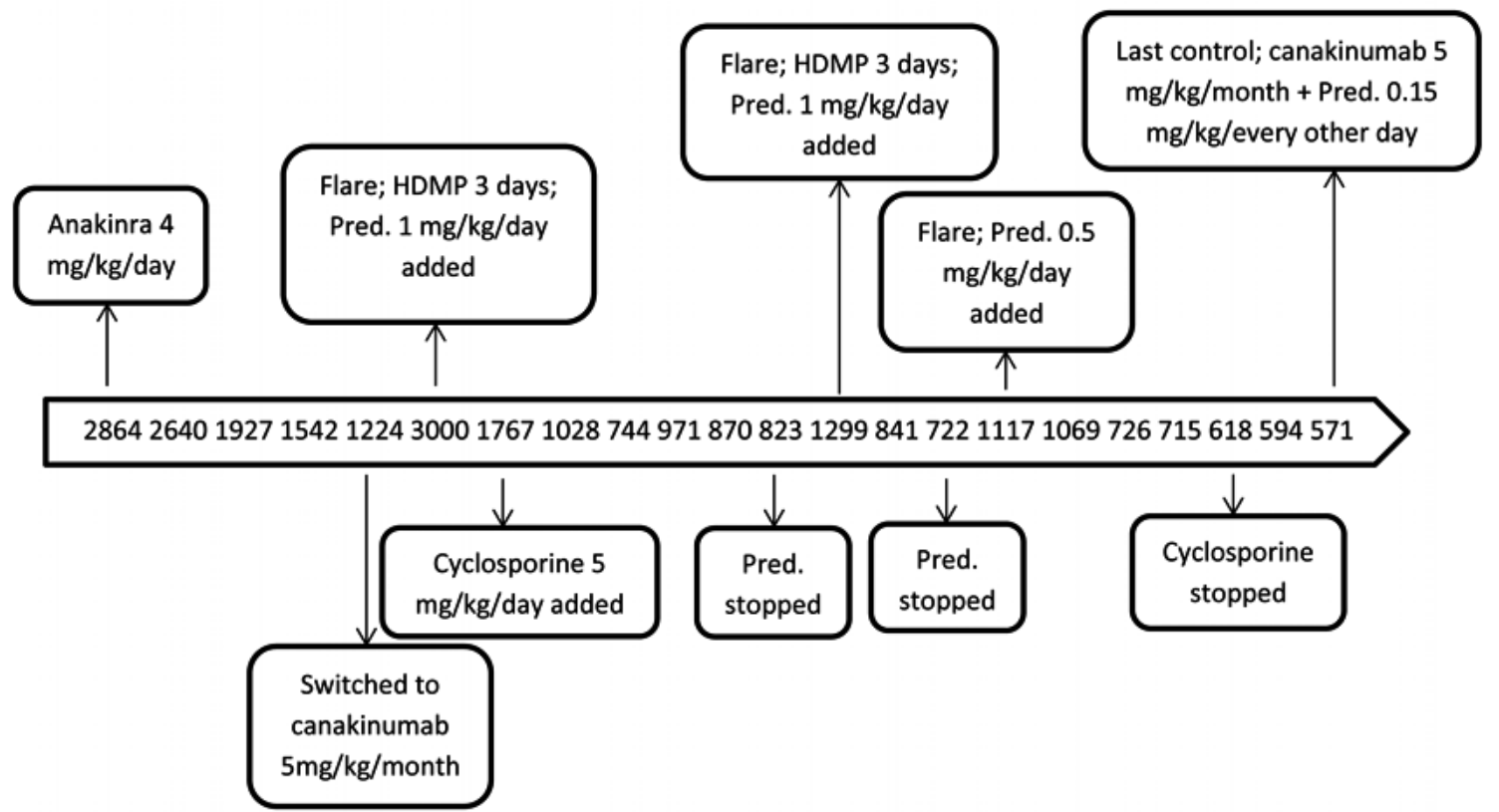

Fig. 1. Monthly checked serum ferritin levels $(\mathrm{ng} / \mathrm{ml})$ and treatment modifications made during 1.5 years of followup.

HDMP: High-dose methylprednisolone (30 mg/kg/day); CRP: C-reactive protein; ESR: Erythrocyte sedimentation rate; Pred: Prednisolone. 
any mass or lymphadenopathy. Broad spectrum antibiotics that were started in the PICU were continued. The clinical picture of the patient was compatible with sJIA and MAS. Highdose methylprednisolone $(30 \mathrm{mg} / \mathrm{kg} /$ day, 3 days) and intravenous immunoglobulin ( $1 \mathrm{~g} /$ $\mathrm{kg}, 2$ days) were given and continued with intravenous prednisolone $(2 \mathrm{mg} / \mathrm{kg} /$ day $)$ and oral cyclosporine $(5 \mathrm{mg} / \mathrm{kg} /$ day $)$. On the $7^{\text {th }}$ day, daily fever peaks continued and laboratory tests showed extreme hyperferritinemia (ferritin: $100.000 \mathrm{ng} / \mathrm{ml}$ ) and worsening in all parameters (Table I $-7^{\text {th }}$ day results). Tuberculin skin test was negative but quantiferon assay analysis became positive on the $7^{\text {th }}$ day so antituberculosis treatment consisting of isoniazid, rifampicin, ethambutol and streptomycin was initiated with the working diagnosis of tuberculous pericarditis.

The clinical picture of the patient was stable but borderline hypotension developed on the $8^{\text {th }}$ day and the child was sent to the PICU of another center for plasma exchange. The next day, he developed respiratory depression and inotrope resistant hypotension in the PICU. He was intubated and ejection fraction was around $20 \%$. Hypotension was unresponsive to all medications, so he was connected to extracorporeal membrane oxygenation (ECMO). The patient spent a month in the PICU. He remained intubated for 13 days, and ECMO was applied for 9 days, plasma exchange for 15 days and continuous veno-venous hemofiltration for 15 days. Control bone marrow aspiration showed hemophagocytic cells. Anti-tuberculosis treatment, prednisolone and cyclosporine were continued in the PICU. He was admitted back to the rheumatology ward after a month. The child still had daily fever peaks and laboratory tests showed persistence of high ferritin levels (ferritin: $8.534 \mathrm{ng} / \mathrm{ml}$ ) and thrombocytopenia (Table I $-35^{\text {th }}$ day results). We were planning to start anakinra from the first day but the child had suspicious tuberculosis infection. As fasting gastric and pericardial fluid cultures and PCR analysis did not yield any positive result for M.tuberculosis and thorax CT was not suggestive of a tuberculosis infection, tuberculosis treatment was discontinued and followed with isoniazid (INH) prophylaxis. Anakinra $4 \mathrm{mg} / \mathrm{kg} /$ day was initiated and finally on the $6^{\text {th }}$ day of anakinra the fever resolved.

On the $2^{\text {nd }}$ month he developed severe midabdominal pain and amylase and lipase levels were elevated. The clinical picture was thought to be cyclosporine induced pancreatitis and cyclosporine was discontinued. Amylase and lipase levels became normalised in 2 weeks. Three weeks later he developed severe local infection on the left inguinal catheter area and fever again. Broad spectrum antibiotics were restarted and as ferritin level rose up to $10.064 \mathrm{ng} / \mathrm{ml}$ anakinra dosage was increased to $8 \mathrm{mg} / \mathrm{kg} /$ day. Wound infection healed totally in 3 weeks. The child was discharged 100 days later with INH and anakinra $(4 \mathrm{mg} /$ $\mathrm{kg} /$ day). He had mild hypertransaminasemia and high ferritin levels (ferritin: $2.864 \mathrm{ng} / \mathrm{ml}$ ) (Table I- $100^{\text {th }}$ day results) during discharge and hypertransaminasemia was thought to be

Table I. Laboratory Parameters of the Patient.

\begin{tabular}{lcccc}
\hline & $1^{\text {st }}$ day & $7^{\text {th }}$ day & $3^{\text {th }}$ day & $100^{\text {th }}$ day \\
\hline Leukocytes & $20.200 / \mathrm{mm}^{3}$ & $12.700 / \mathrm{mm}^{3}$ & $4900 / \mathrm{mm}^{3}$ & $10.500 / \mathrm{mm}^{3}$ \\
Hemoglobin & $8.2 \mathrm{~g} / \mathrm{dl}$ & $12.9 \mathrm{~g} / \mathrm{dl}($ transfused $)$ & $12.1 \mathrm{~g} / \mathrm{dl}$ & $11.5 \mathrm{~g} / \mathrm{dl}$ \\
Platelets & $553.000 / \mathrm{mm}^{3}$ & $80.000 / \mathrm{mm}^{3}$ & $68.000 / \mathrm{mm}^{3}$ & $354.000 / \mathrm{mm}^{3}$ \\
CRP & $154 \mathrm{mg} / \mathrm{L}$ & $19.4 \mathrm{mg} / \mathrm{L}$ & $28 \mathrm{mg} / \mathrm{L}$ & $0.5 \mathrm{mg} / \mathrm{L}$ \\
ESR & $95 \mathrm{~mm} / \mathrm{hr}$ & $12 \mathrm{~mm} / \mathrm{hr}$ & $30 \mathrm{~mm} / \mathrm{hr}$ & $10 \mathrm{~mm} / \mathrm{hr}$ \\
Albumin & $2.2 \mathrm{~g} / \mathrm{dl}$ & $2.4 \mathrm{~g} / \mathrm{dl}$ & $3.2 \mathrm{~g} / \mathrm{dl}$ & $3.8 \mathrm{~g} / \mathrm{dl}$ \\
AST & $42 \mathrm{U} / \mathrm{L}$ & $1209 \mathrm{U} / \mathrm{L}$ & $35 \mathrm{U} / \mathrm{L}$ & $114 \mathrm{U} / \mathrm{L}$ \\
ALT & $19 \mathrm{U} / \mathrm{L}$ & $582 \mathrm{U} / \mathrm{L}$ & $20 \mathrm{U} / \mathrm{L}$ & $139 \mathrm{U} / \mathrm{L}$ \\
Ferritin & $13.670 \mathrm{ng} / \mathrm{ml}$ & $100.000 \mathrm{ng} / \mathrm{ml}$ & $8.534 \mathrm{ng} / \mathrm{ml}$ & $2.864 \mathrm{ng} / \mathrm{ml}$ \\
Triglyceride & $199 \mathrm{mg} / \mathrm{dl}$ & $678 \mathrm{mg} / \mathrm{dl}$ & $335 \mathrm{mg} / \mathrm{dl}$ & $175 \mathrm{mg} / \mathrm{dl}$ \\
LDH & $489 \mathrm{U} / \mathrm{L}$ & $2091 \mathrm{U} / \mathrm{L}$ & $223 \mathrm{U} / \mathrm{L}$ & $155 \mathrm{U} / \mathrm{L}$ \\
\hline
\end{tabular}

CRP: C-reactive protein; ESR: erythrocyte sedimentation rate; AST: aspartate aminotransferase; ALT: alanine aminotransferase; LDH: lactate dehydrogenase. 
INH side effect and INH was discontinued for 2 weeks and restarted after normalization of liver function tests. Four months later anakinra was switched to canakinumab (5 mg/kg/month) due to painful daily injections.

He has been followed for 1.5 years and had three flares of sJIA during this period. In every flare he had fever for 2 or 3 days without any other symptom or sign and all flares were seen 2-3 weeks after drug modifications. Figure 1 shows ferritin levels that were checked every month and treatment modifications that were made. The main question was although he was clinically stable and all other laboratory parameters were normal why ferritin levels were still high. So we looked for familial HLH genes namely PRF1, UNC13D, and STX11. We found heterozygous A91V variant in the perforin gene. The mother and brother had wild type gene but the father had heterozygous A91V variant too. The child was consulted to pediatric hematology team for bone marrow transplantation (BMT). After consideration of benefits and harms of BMT and discussions with the family, the decision was that although he was a candidate for BMT, it should not be considered as an option at the moment as the child was doing well with the current medical treatment.

The child is currently stable on monthly canakinumab $(5 \mathrm{mg} / \mathrm{kg})$ and oral prednisolone $0.15 \mathrm{mg} / \mathrm{kg} /$ every other day. Physical and laboratory examinations are normal by all parameters except for hyperferritinemia that is fluctuating around $500 \mathrm{ng} / \mathrm{ml}$. Informed consent was received from the family.

\section{Discussion}

A thorough review of the literature via PubMed search (2004-2017; terms: perforin $\mathrm{A} 91 \mathrm{~V}$, systemic juvenile idiopathic arthritis, macrophage activation syndrome, hemophagocytic lymphohistiocytosis, hyperferritinemia) was performed to retrieve data regarding the perforin mutations and macrophage activation syndrome secondary to systemic juvenile idiopathic arthritis.

Hemophagocytic lymphohistiocytosis is a term that is used to describe a spectrum of disorders characterized by accumulation of well-differentiated mononuclear cells with a macrophage phenotype exhibiting hemophagocytic activity. ${ }^{3,6} \mathrm{HLH}$ is divided as primary (familial) $\mathrm{HLH}$ and secondary HLH. Secondary HLH may be caused by infectious, oncologic and rheumatologic etiologies and when caused by rheumatologic disorders, it is traditionally called MAS. ${ }^{4}$ The most common cause of rheumatologic disorder associated with MAS in children is sJIA. sJIA is a subtype of JIA and is characterized by arthritis, fever, rash, serositis, hepatosplenomegaly and lymphadenopathy. ${ }^{8}$ MAS is a severe and potentially lethal complication of sJIA. Clinical features are non-remitting high fever, hepatosplenomegaly, lymphadenopathy, hemorrhages and central nervous system dysfunction. On laboratory tests cytopenias, abnormal liver function tests, decreased erythrocyte sedimentation rate (due to consumption of fibrinogen), hypertriglyceridemia, hyponatremia, hypoalbuminemia, elevated levels of serum sCD25 and cCD163 levels, hemophagocytosis on tissue examinations, and most strikingly hyperferritinemia are observed. 3,8 Our case had all clinical and laboratory features of sJIA and severe MAS that could not have been controlled with medical treatment and needed plasma exchange and ECMO.

Familial HLH (fHLH) is a group of rare autosomal recessive disorders caused by genetic defects in packaging, exocytosis or function of cytotoxic granules leading to inability of natural killer cells and cytotoxic $\mathrm{T}$ cells to kill targeted cells causing an overwhelming inflammatory response and excessive cytokine production resulting in sustained macrophage activation. ${ }^{3,6,9}$ There are 5 types of fHLH and also some immune deficiency disorders like Griscelli syndrome, Chédiak-Higashi syndrome, Hermansky-Pudlak syndrome type II, X-linked lymphoproliferative syndromes and many others may cause to fHLH. ${ }^{4,9}$ The clinical and laboratory features are very similar in fHLH and secondary HLH. To differentiate sJIA complicated with MAS from primary and other secondary forms of HLH, several classification/ diagnostic criteria sets have been developed. ${ }^{8}$ The age of onset is less than 1 year of age in $70 \%$ of $\mathrm{fHLH}$ cases but there is no known upper age limit for the onset of the disease and the only curative method is bone marrow transplantation. ${ }^{9}$ 
Perforin is a pore-forming protein that is critical for the function of cytotoxic lymphocytes in immune responses to microorganisms and in surveillance for malignancies.9,10 The most common cause of fHLH is perforin deficiency (type $2 \mathrm{fHLH}$ ) and mutations in the perforin gene (PRF1) accounts for $20-50 \%$ of $\mathrm{fHLH}$ cases, while mutations in three other genes, UNC13D, STX11, and STXBP2 (type 3,4,5 $\mathrm{fHLH}$, respectively) impair the delivery of perforin into the immune synapse. $3,7,10,11$ fHLH type 1 is linked to the 9q21.3 locus, comprises around $10 \%$ of fHLH cases and can be recognized by impaired natural killer cell function but not associated with the absence of perforin expression. ${ }^{9}$ It is clear that homozygote pathogenic mutations in fHLH genes result in fatal illness that mostly present under 2 years of age. But there are some cases that carry mutations in fHLH genes and do not fit to this category and Voskoboinik et al. ${ }^{7}$ proposed the term perforinopathy to consider functional perforin deficiencies as a spectrum of clinical presentations and not as a single disease entity. They suggested that the term acute perforinopathy should be used to describe cases with classical fHLH that is diagnosed under 2 years of age with bi-allelic mutations in fHLH genes leading to complete loss-of-function. Sub-acute perforinopathy term was suggested for cases with inflammatory disease that has remitting/relapsing course that presented after 2 years of age with bi-allelic mutations in fHLH genes leading to partial loss-of-function. Chronic perforinopathy term was suggested to be used in patients presenting during adolescence or adulthood with MAS, hematological malignancy, or lymphoproliferative disease and having mono-allelic mutations in the PRF1 gene. Most importantly, mono-allelic mutations in the PRF1 gene (most commonly A91V variant) were considered as a contributing factor but not as a causative factor. ${ }^{7}$

Several studies have shown that patients with sJIA have dysfunction of natural killer cells. ${ }^{12}$ Vastert et al. ${ }^{10}$ have shown that at the time of MAS in sJIA patients there were even more marked decreases in perforin levels of natural killer cells along with a further decrease of lytic natural killer cell function. In the same study, 56 sJIA patients were analyzed for PRF1 gene mutations and $11(20 \%)$ of them were found to be heterozygous for missense mutations in PRF1 (7 of them had A91V variant). Interestingly, heterozygosity for A91V was twice as frequent in sJIA patients with a history of MAS compared with sJIA patients without a history of MAS (20 vs 9.8). The authors concluded that low perforin expression and lytic function of natural killer cells in sJIA patients were further depressed during MAS and having heterozygous mutations in the PRF1 gene could be a risk factor for MAS development in sJIA patients. ${ }^{10}$ Huasong et al. ${ }^{13}$ studied A91V gene analysis in 31 MAS cases and no variant was found and they concluded that ethnic and regional differences may play a role in the pathogenesis.

A91V sequence variation in PRF1 gene is considered as a neutral polymorphism by some authors. They state that carriage rate of $\mathrm{A} 91 \mathrm{~V}$ in the Caucasian population is as high as $17.5 \%-21 \%$, so the incidence of HLH should be much higher than observed in population. ${ }^{14,15}$ In papers that considered A91V as a pathogenic mutation, all cases were older children or young adults having atypical fHLH features and the authors commented that probably this was not definitive causative factor but contributing. ${ }^{16-18}$ Okur et al. ${ }^{19}$ looked for the frequency of $\mathrm{A} 91 \mathrm{~V}$ sequence variant in 44 secondary HLH patients and found that $5(11.3 \%)$ of them had A91V mutation and all of the patients had an infection. In the same study they searched for the frequency of A91V variant in 159 healthy Turkish controls and found that 7 (4.4\%) of them had A91V variation. They concluded that A91V mutation is not uncommon in the general population but having this mutation increases the risk of secondary HLH in patients with an underlying condition, especially those with an underlying infection. Also, there are some studies stating that having heterozygous A91V variant in the PRF1 gene could predispose individuals to leukemia, lymphoma and melanoma. ${ }^{7,20-22}$

In our clinic, we do not normally check any fHLH genes in sJIA patients with or without MAS. We wanted to look for perforin and other fHLH gene mutations for this patient because the patient's course was extremely unusual for a sJIA-MAS patient. MAS attack was very severe which needed ECMO and plasma exchange and more importantly after normalization of clinical and all other laboratory parameters ferritin 
levels did not get back to normal. We also do not think that A91V variant was a causative factor for MAS but was a contributing factor in our case. The limitation of our manuscript is that we were unable to perform any functional studies and measure cytokine levels.

In conclusion, like many authors, we think that having heterozygous PRF1 gene variants - with some residual perforin activity - may cause late onset and atypical MAS attacks when encountered with a triggering factor and we recommend checking for PRF1 gene in these cases.

\section{REFERENCES}

1. Benedetti FD, Schneider R. Systemic Juvenile Idiopathic Arthritis. In: Petty RE, Laxer RM, Lindsey CB, Wedderburn LR (eds). Textbook of Pediatric Rheumatology (7th ed). Philadelphia: Elsevier, 2016: 205-216.

2. Gowdie PJ, Tse SM. Juvenile idiopathic arthritis. Pediatr Clin N Am 2012; 59: 301-327.

3. Ravelli A, Grom AA, Behrens EM, Cron RQ. Macrophage activation syndrome as part of systemic juvenile idiopathic arthritis: Diagnosis, genetics, pathophysiology and treatment. Genes Immune2012; 13: $289-298$

4. Cron RQ, Davi S, Minoia F, Ravelli A. Clinical features and correct diagnosis of macrophage activation syndrome. Expert Rev Clin Immunol 2015; 11: 10431053.

5. Celkan T, Berrak S, Kazanci E, et al. Malignancyassociated hemophagocytic lymphohistiocytosis in pediatric cases: A multicenter study from Turkey. Turk J Pediatr 2009; 51: 207-213.

6. Canna SW, Behrens EM. Making sense of the cytokine storm: A conceptual framework for understanding, diagnosing, and treating hemophagocytic syndromes. Pediatr Clin North Am 2012; 59: 329-344.

7. Voskoboinik I, Trapani JA. Perforinopathy: A spectrum of human immune disease caused by defective perforin delivery or function. Front Immunol 2013; 4: 441.

8. Boom V, Anton J, Lahdenne P, et al. Evidence-based diagnosis and treatment of macrophage activation syndrome in systemic juvenile idiopathic arthritis. Pediatr Rheumatol Online J 2015; 13: 55.

9. Arceci RJ. Histiocytosis Syndromes. In: Lanzkowsky P (ed) Manual of Pediatric Hematology and Oncology (5th ed). Philadelphia: Elsevier, 2011: 567-598.

10. Vastert SJ, van Wijk R, D'Urbano LE, et al. Mutations in the perforin gene can be linked to macrophage activation syndrome in patients with systemic onset juvenile idiopathic arthritis. Rheumatology (Oxford) 2010; 49: 441-449.
11. Albayrak M, Kaya Z, Yilmaz-Keskin E, Stadt UZ, Koçak U, Gürsel T. Fatal Epstein-Barr virus infection in a case of familial hemophagocytic lymphohistiocytosis with syntaxin-11 mutation. Turk J Pediatr 2009; 51: 371-374.

12. de Jager W, Vastert SJ, Beekman JM, et al. Defective phosphorylation of interleukin-18 receptor beta causes impaired natural killer cell function in systemic-onset juvenile idiopathic arthritis. Arthritis Rheum 2009; 60: 2782-2793.

13. Huasong Z, Ping W, Xiangyuan C, Yandan W. Clinical features and perforin A91V gene analysis in 31 patients with macrophage activation syndrome and systemic juvenile idiopathic arthritis in China. J Rheumatol 2013; 40: 1238-1239.

14. Mancebo E, Allende LM, Guzmán M, et al. Familial hemophagocytic lymphohistiocytosis in an adult patient homozygous for A91V in the perforin gene, with tuberculosis infection. Haematologica 2006; 91: 1257-1260.

15. Zur Stadt U, Beutel K, Weber B, Kabisch $\mathrm{H}$ Schneppenheim R, Janka G. A91V is a polymorphism in the perforin gene not causative of an FHLH phenotype. Blood 2004; 104: 1909.

16. Busiello R, Adriani M, Locatelli F, et al. Atypical features of familial hemophagocytic lymphohistiocytosis. Blood 2004; 103: 4610-4612.

17. Clementi R, Emmi L, Maccario R, et al. Adult onset and atypical presentation of hemophagocytic lymphohistiocytosis in siblings carrying PRF1 mutations. Blood 2002; 100: 2266-2267.

18. Okur H, Balta G, Akarsu N, et al. Clinical and molecular aspects of Turkish familial hemophagocytic lymphohistiocytosis patients with perforin mutations. Leuk Res 2008; 32: 972-975.

19. Okur H, Ünal Ş, Balta G, et al. The frequency of A91V in the perforin gene and the effect of tumor necrosis factor- $\alpha$ promoter polymorphism on acquired hemophagocytic lymphohistiocytosis. Turk J Haematol 2011; 28: 125-130.

20. Santoro A, Cannella S, Trizzino A, Lo Nigro L, Corsello G, Aricò M. A single amino acid change A91V in perforin: A novel, frequent predisposing factor to childhood acute lymphoblastic leukemia? Haematologica 2005; 90: 697-698.

21. Trapani JA, Thia KY, Andrews M, et al. Human perforin mutations and susceptibility to multiple primary cancers. Oncoimmunology 2013; 2: e24185.

22. Chaudhry MS, Gilmour KC, House IG, et al. Missense mutations in the perforin (PRF1) gene as a cause of hereditary cancer predisposition. Oncoimmunology 2016; 5: e1179415. 